\title{
Experimentation of a novel composite phase change material for thermal comfort improvement and energy saving in buildings
}

\author{
Boussaba $\mathrm{L}^{1 *}$, Makhlouf $\mathrm{S}^{2}$, Foufa $\mathrm{AA}^{1}$
}

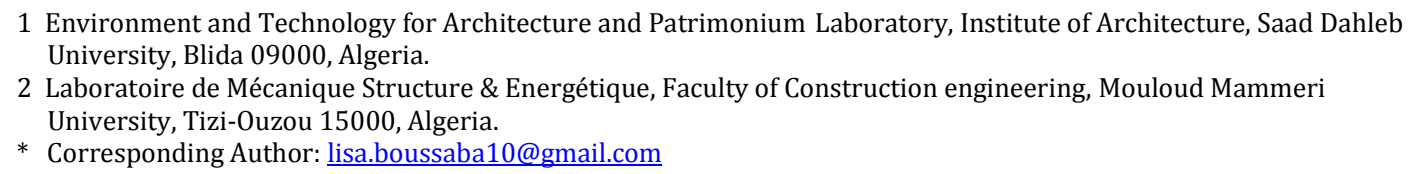

Received: 08-02-2018

Revised: 24-03-2018

Accepted: 08-04-2018

\begin{abstract}
This study focuses on the preparation of a novel composite phase change material (PCM) for an application of Latent Heat Thermal Energy Storage in buildings. The aim of this application is to improve thermal inertia in buildings. A good thermal inertia, involves the improvement of thermal comfort and energy saving. The experimented materials components are selected for their availability, safety and low cost. Paraffin with a melting temperature range close to $30^{\circ} \mathrm{C}$ is selected as a PCM; it is composed of microcrystalline wax and liquid paraffin. The matrix is prepared from plaster, graphite powder and cellulose fibers. The PCM is introduced in the matrix following the immersion method. Several samples are prepared; there after they are subjected to a thermal treatment at $50^{\circ} \mathrm{C}$ for 30 min on a filter paper. The purpose is to identify the performance of each sample to retain the PCM without leakages.

Thermal and physicochemical characterizations are performed to study the composites' properties: Scanning Electron Microscopy (SEM) is used to observe its microstructure; X-Ray Diffraction (XRD) identifies the crystallographic structure of the composite-PCM while Fourier Transformed Infrared Spectroscopy (FT-IR) reveals the chemical compatibility between its different components. Thermo Gravimetric Analysis (TGA) and Differential Scanning Calorimetry (DSC) are performed for thermal characterization. The thermal performance of the composite-PCM is verified experimentally using thermocouple measurements connected to a temperature recorder apparatus. The measurements are done simultaneously on two pellets; the first contains PCM while the second does not contain PCM.
\end{abstract}

Key words: Composite-PCM, Thermal inertia, Buildings, Thermal characterization, Physico-chemical characterization.

\section{Introduction}

Today, thermal comfort in buildings is mostly ensured using heating and air conditioning systems. However, the building sector becomes one of the leader consumers of fossil energies. It is also responsible for gas emissions which lead to greenhouse effect and global warming.

Thermal energy storage (TES) is known as a promising technique for energy supplying in the future. Thermal energy may be stored as sensible heat or latent heat (Garg et al., 1985). In buildings with massive masonry or concrete walls (Voelker et al., 2008), the thermal comfort in the summer is ensured thanks to the high heat capacity of their massive components. In this case, the thermal comfort is obtained with the Sensible Heat Storage (SHS) concept. In contrast, the thermal comfort is not ensured with SHS in lightweight constructions because of their low heat capacity. So, Phase Change Materials (PCMs) are used to ensure the thermal comfort with the Latent Heat Thermal Energy Storage (LHTES) concept. Unlike sensible heat storage, LHTES provides higher energy storage. Researchers found that the use of PCMs can provide a desirable alternative to rock storage (Berroug et al., 2011) because in PCMs systems, the heat is stored and 
released at a constant temperature (Pasupathy et al., 2008). Thus, the indoor temperatures in buildings are stabilized. For these reasons, the use of PCMs for LHTES became a topic with a lot of interest within architects and engineers in the last decades (Cabezaa et al., 2011) and recognized as an innovative energy saving strategy for a sustainable built environment (Wahid et al., 2016).

PCMs are divided into three main groups: organic compounds, inorganic compounds and eutectics (Sharma et al., 2009). The organic PCMs include paraffin and fatty acids while the inorganic ones are salt hydrates. Eutectics are mixtures of organic-organic PCMs, inorganicinorganic PCMs or organic-inorganic ones (Pielichowska et al., 2014).

Each class of PCM has its own advantages and disadvantages. The organic PCMs are the most used in the building industry because they are available in broad range of melting temperatures, chemically stable, non-corrosive and none supercooling but they have low thermal conductivity (Sari and Karaipekli, 2007).

Researchers have reported that there are three promising methods of incorporating PCMs into the conventional building materials. These methods are: direct incorporation, immersion method and encapsulation (Zhou et al., 2008); the first and the second methods are the simplest ones.

In the present study, the immersion method of the experimented material in the melted PCM is followed. Since the immersion consists of absorbing PCMs into the internal pores of the building material, a composite material (based on mineral powder) for which the porosity is improved by the incorporation of cellulose fibers is prepared. It is known that wastes from industrial or agricultural productions lead the formation of pores when they are incorporated in building materials (Bories et al, 2014). So in the present work, the incorporated fibers are obtained from recycling paper. The purpose is also to recover an organic waste material. The experimented material is then low-cost and environmentally ecofriendly.

Paraffin with a melting temperature range close to the temperature of human comfort $\left(30^{\circ} \mathrm{C}\right)$ is chosen as a PCM for its safety and availability. Despite its desirable properties, paraffin is an organic PCM which has low thermal conductivity (Zalba et al., 2003). That is why graphite is added in order to improve the thermal conductivity.

The prepared composite-PCM is characterized by a Scanning electron microscopy (SEM) to observe its microstructure. Both X-Ray Diffraction (XRD) and Fourier transformed infrared spectroscopy (FT-IR) are used for chemical characterization. The thermal characterization is done with Differential scanning Calorimetry (DSC) when Thermo Gravimetric Analysis (TGA) is used for the thermal reliability analysis. The thermal performance of the composite-PCM is verified experimentally on two pellets. The first contains the PCM while the second does not contain the PCM. The test is performed simultaneously on two samples using thermocouples measurement connected to a temperature recorder apparatus.

\section{Experimental}

\subsection{Materials}

Paraffin is an organic compound chosen as a PCM Fig 1 (d) for its melting temperature range close to the temperatures of human comfort $\left(30^{\circ} \mathrm{C}\right)$, its safety, availability and low cost. It is recovered from health facilities and pharmacies.

A composite matrix composed essentially of Plaster powder Fig 1 (b) and cellulose fibers Fig 1 (a) is prepared.

Graphite Fig 1 (c) is added to the composite in order to improve its thermal conductivity. 
Table 1 displays the particle size parameters of the plaster used in the experiment and Fig 2 shows its size distribution curve.

The cellulose fibers are obtained from recycling of waste paper. It is introduced to the matrix in order to improve its porosity and its PCM absorption capacity.
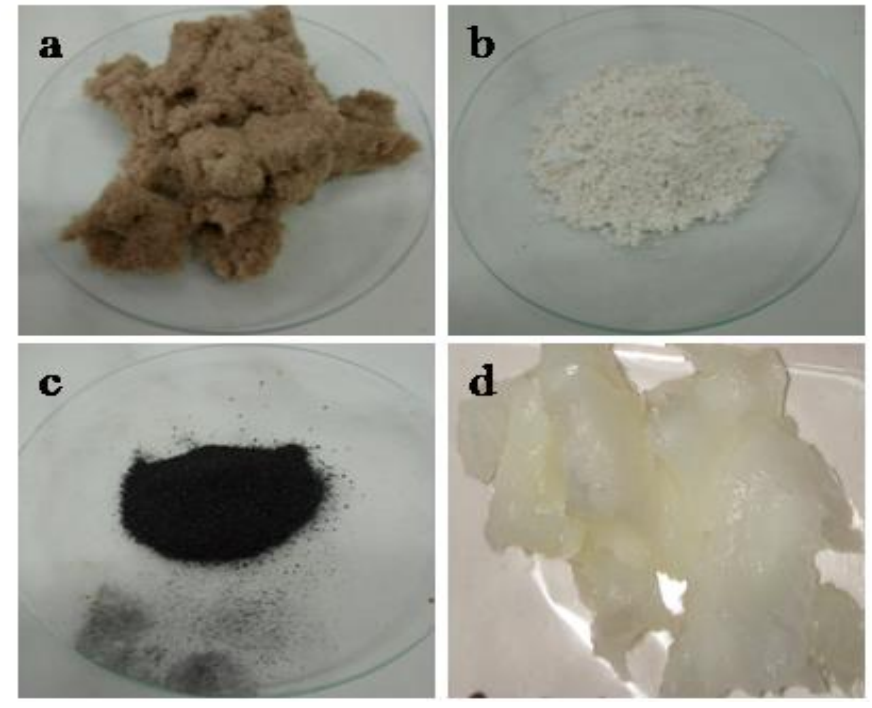

Fig 1. The photographs of: a) Cellulose fibers, b) Plaster, c) Graphite, d) Paraffin.

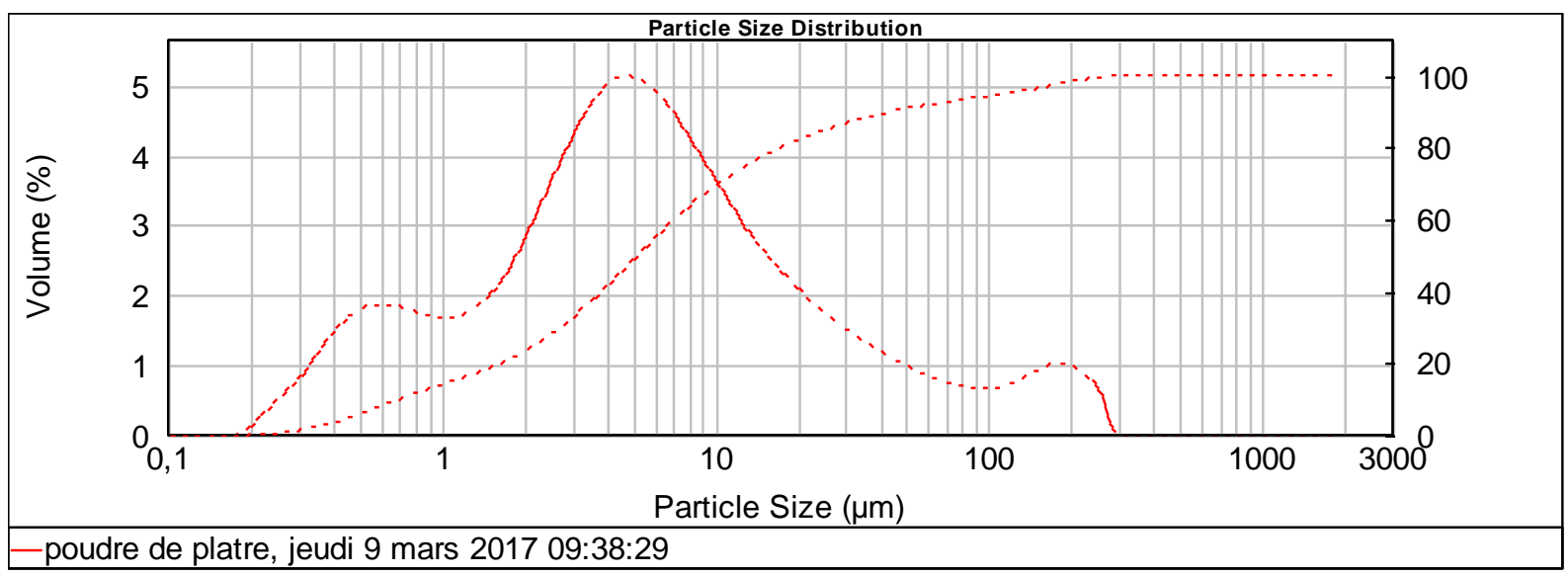

Fig 2. The particle size distribution curve of plaster powder used in the experiment.

Table 1. Particle size distribution parameters of plaster powder used in the experiment.

\begin{tabular}{|c|c|c|c|c|}
\hline Sample & $\mathrm{d}(0.1)$ & $\mathrm{d}(0.5)$ & $\mathrm{d}(0.9)$ & $\mathrm{s} / \mathrm{g}\left(\mathrm{m}^{2} / \mathrm{g}\right)$ \\
\hline \hline Plaster powder values (um) & 0.707 & 5.186 & 43.699 & 2.9 \\
\hline
\end{tabular}

\subsection{Preparation of the composite plaster/cellulose fibers/graphite/PCM}

Before elaborating the composite-PCM, the matrix which supports the PCM is prepared first. So, components listed above (plaster powder, cellulose fibers and graphite) are mixed together. The purpose is to coat cellulose fibers with a thin layer of plaster powder and to make a regular distribution of graphite into the matrix. Subsequently, the previous mixture is poured into the water.

The resulting past is poured in a rectangular molded and a slight uniaxial compression is performed to form rectangular pellets. The pellets are dried in an oven at $100^{\circ} \mathrm{C}$ for 24 hours. 
Following the previous process, several samples with different mass fractions of components are prepared. The goal is to identify which matrix is able to contain the best rate of PCM without consequent leakages.

The composite-PCM is prepared following the single face immersion method of the prepared pellets (the matrix) in the melted PCM. A thermal treatment is then performed on a filter paper at $50{ }^{\circ} \mathrm{C}$ for 30 minutes in order to test the performance of each sample to retain the PCM in its melted state. Table 2 lists the absorption rates of the best pellets selected before and after thermal treatment. Fig 3 (A) shows the pellet sample placed on a filter paper before the thermal treatment and Fig 3 (B.1 B.5) shows the respective fat stains of pellets (COMPI COMPV) obtained after thermal treatment on filter paper.

Table 2. PCM absorption rates of the selected samples.

\begin{tabular}{|c|c|c|c|c|c|}
\hline Samples & Comp I & Comp II & Comp III & Comp IV & Comp V \\
\hline \hline $\begin{array}{c}\text { PCM absorption rate: before } \\
\text { thermal treatment (wt \%) }\end{array}$ & 47.58 & 49.81 & 59.15 & 64.58 & 80.57 \\
\hline $\begin{array}{c}\text { PCM absorption rate: after } \\
\text { thermal treatment (wt \%) }\end{array}$ & 47.31 & 49.48 & 58.88 & 64.36 & 80.39 \\
\hline
\end{tabular}
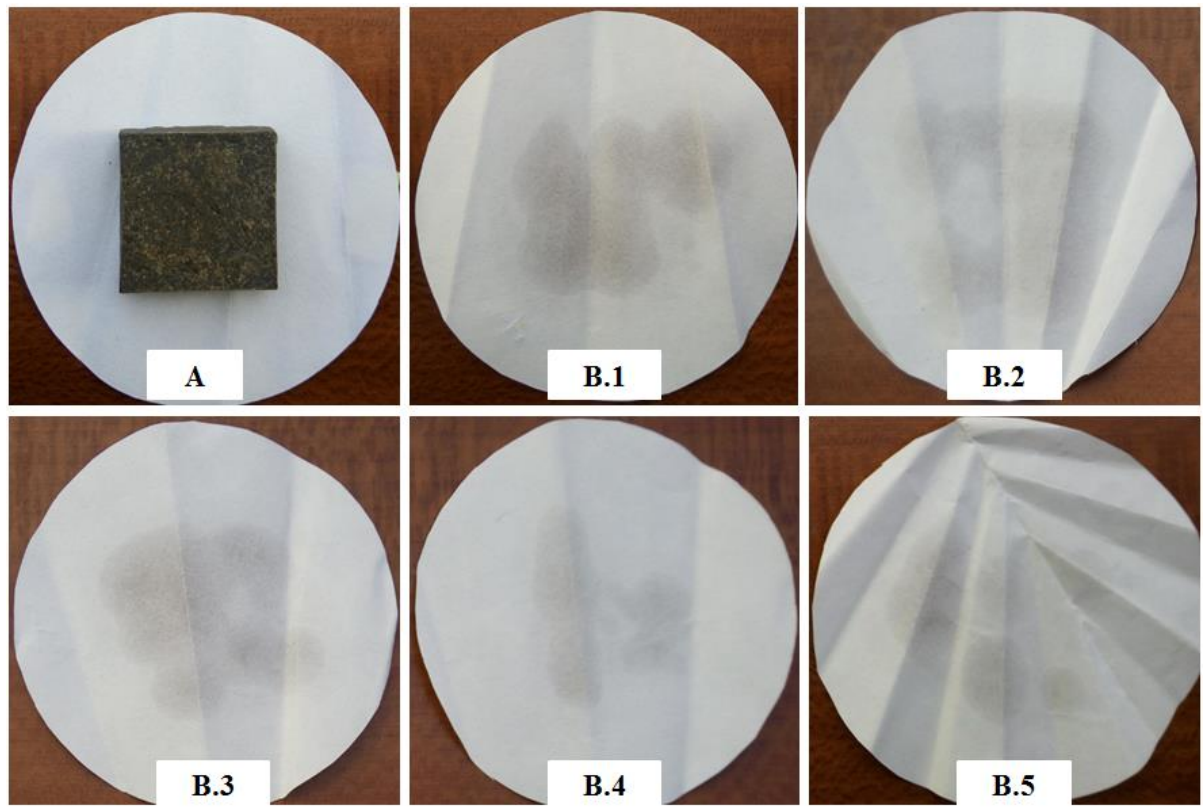

Fig 3. Photographs of: A) Pellet sample before thermal treatment; B.1 B.5) the respective fat stains of COMPI COMPV after thermal treatment.

\subsection{Characterization of the composite-PCM}

Scanning Electron Microscopy (SEM) is performed to observe the microstructure of the composite before and after its immersion in the PCM. The material is observed under different magnifications and $30 \mathrm{KV}$ of tension acceleration. (FEI QUANTA $650 \mathrm{SEM}$ ) is used.

Both Fourier Transformed Infrared Spectroscopy (FT-IR) and X-Ray Diffraction (XRD) are carried out for chemical characterization. The FT-IR spectra of the different $\mathrm{KBr}$ pellets are recorded using (JASCO FT/IR-4100 spectrophotometer) in a transmission mode under frequency range between $4000 \sim 400 \mathrm{~cm}^{-1}$.

XRD pattern of the composite-PCM is obtained using (D2-PHASER BRUKER X-Ray Diffractometer). The crystallographic structure analysis is done under $\mathrm{Cu}-\mathrm{Ka}$ and $(\Lambda=1.541874$ 


\section{Å) irradiation.}

The thermal reliability of the composite-PCM is tested with Thermo Gravimetric Analysis technique (TGA); (STA PT 1600 of LIENSEIS) Thermo gravimetric apparatus is used for this purpose. The sample of $7 \mathrm{mg}$ is placed in an alumina crucible and TGA test is performed from room temperature $\left(20^{\circ} \mathrm{C}\right)$ to $560^{\circ} \mathrm{C}$ with a heating rate of $10^{\circ} \mathrm{C} /$ minute.

(DSC Q100 of TA instrument) apparatus is used for Differential Scanning Calorimetry characterization (DSC). Heating cycles are performed on both the PCM and the composite-PCM. (COMP.V) is selected for the DSC test because of its best absorption rate of PCM. So, $8.4 \mathrm{mg}$ of each the PCM and (COMP.V) are placed in alumina crucibles and tested under nitrogen atmosphere $\left(\mathrm{N}_{2}\right)$. DSC analysis is carried out with $5{ }^{\circ} \mathrm{C} /$ minute of heating rates from $-10{ }^{\circ} \mathrm{C}$ to $60^{\circ} \mathrm{C}$.

Fig 4 shows the schematic experimental protocol adopted for testing the difference in thermal performance between a sample which contains PCM and another sample which does not contain PCM. Six thermocouples type K connected to the temperature recorder apparatus PICOLOG TC08 are used.

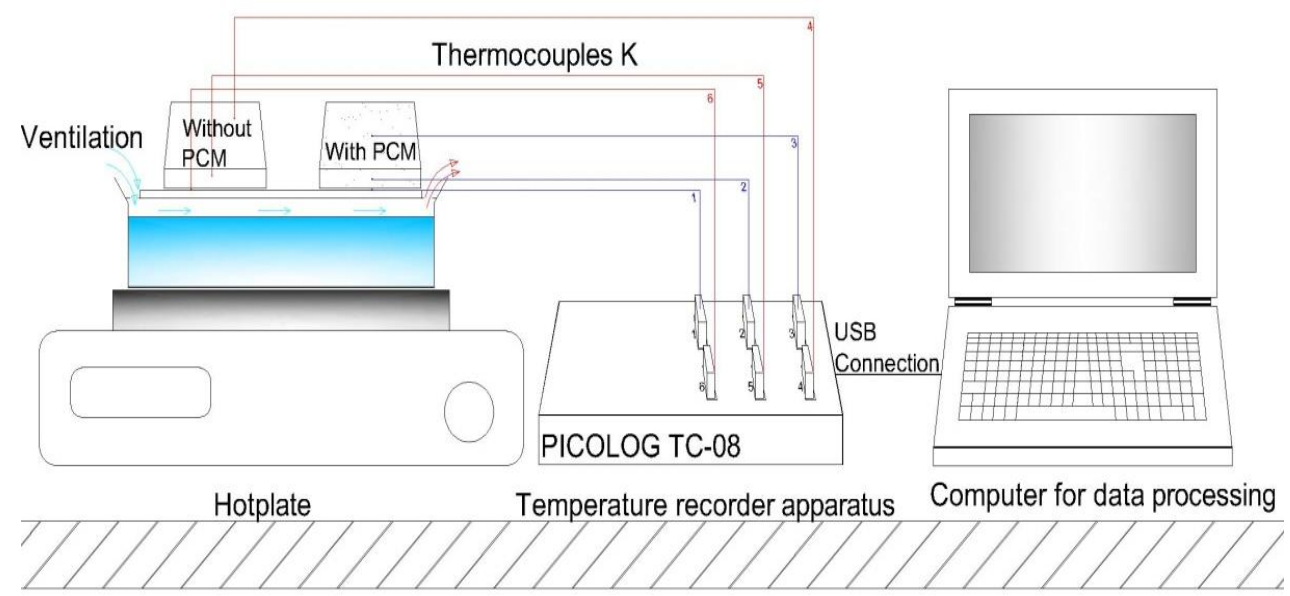

Fig 4. Procedure for measuring the thermal performance of the composite-PCM

\section{Results and discussion}

\subsection{Morphology and microstructure of the composite}

Fig 5 shows the ESEM photographs of the composite before the incorporation of the PCM, and the distribution of the PCM in the microstructure of this composite after the immersion process.

Fig 5 (a), (b), (c) show the morphology of the composite matrix under different magnifications (x9500, x2400, x100 respectively) before the incorporation of the PCM.

As seen in Fig 5, the matrix presents an accidental and rough microstructure. The adhesion of gypsum molecules to the cellulose fibers improves the roughness of the matrix.

Fig 5 (d), (e), (f) show the regular distribution of the PCM into the matrix and into the microstructure of cellulose fibers. The PCM is incorporated uniformly into the microstructure of its container.

As a conclusion, the morphology of the composite matrix presents favorable properties for absorbing and containing the PCM in its microstructure. The PCM is absorbed and retained thanks to the capillary and surface tension forces of the matrix. 

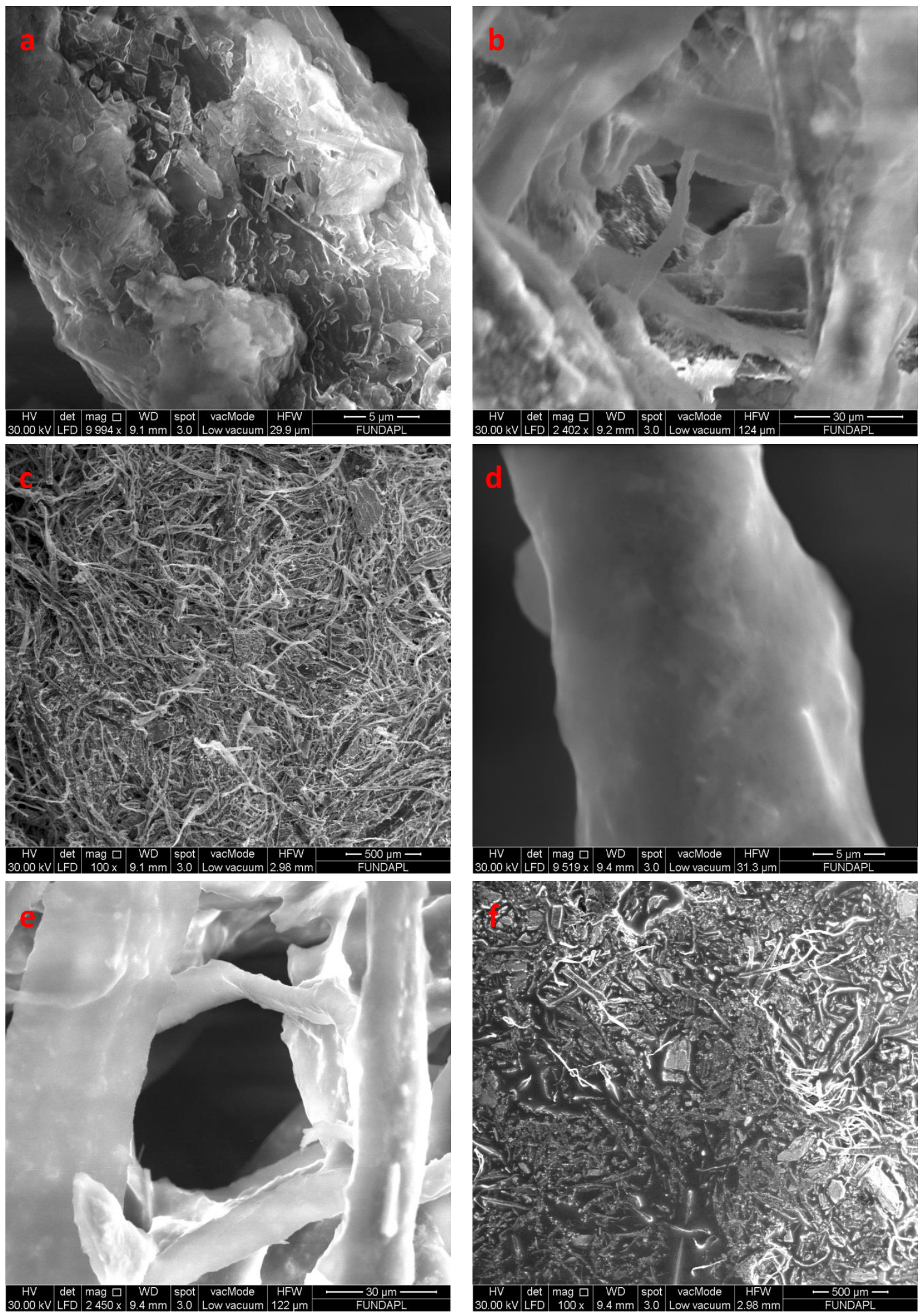

Fig 5. ESEM photographs of: (a), (b), (c) microstructure of the matrix. (d), (e), (f) microstructure of the composite-PCM. 


\subsection{FT-IR for chemical compatibility analysis}

Fig 6 shows the IR spectra of the composite-PCM and its components. FT-IR is performed in order to verify the chemical compatibility between the different components of the compositePCM. As seen from Fig 6, cellulose fibers spectrum shows the presence of $-\mathrm{CH}_{2}$ bending peak at $1432 \mathrm{~cm}^{-1} \cdot \mathrm{C}_{6} \mathrm{H}_{10} \mathrm{O}_{5}$ is the chemical formula of cellulose (Klemm et al., 2005). The peak reported at $1641 \mathrm{~cm}^{-1}$ corresponds to C-O bending. The bending peaks at $1100 \mathrm{~cm}^{-1}$ and $1500 \mathrm{~cm}^{-1}$ are related to $\mathrm{C}-\mathrm{H}$ stretching vibrations. (Hinterstoisser et al., 2001) studied FT-IR of cellulose fibers.

The PCMs' spectrum displays characteristic absorption bands of alkanes at $2922 \mathrm{~cm}^{-1}$ and 2855 $\mathrm{cm}^{-1}$. The characteristic band reported at $1630 \mathrm{~cm}^{-1}$ corresponds to $\mathrm{CH}_{2}$ group. The peak at 1380 $\mathrm{cm}^{-1}$ refers to methyl groups which are hydrophobic groups. This result is confirmed by (Peterson et al., 2008).

It is observed in the composite-PCM spectrum the presence of specific peaks of $\mathrm{C}-\mathrm{H}$ bands at $2847 \mathrm{~cm}^{-1}$ and $2914 \mathrm{~cm}^{-1}$ wavenumbers. Similar specific peaks are reported in the PCMs' spectrum at $2855 \mathrm{~cm}^{-1}$ and $2922 \mathrm{~cm}^{-1}$ and at cellulose fibers spectrum. After comparison between the different obtained spectra, it is clearly visible that there is no shift in peaks of the compositePCM compared to those of its components.

The result means that there is no chemical interaction between the different components of the composite-PCM. The combination is only physical. So, the material is chemically stable.

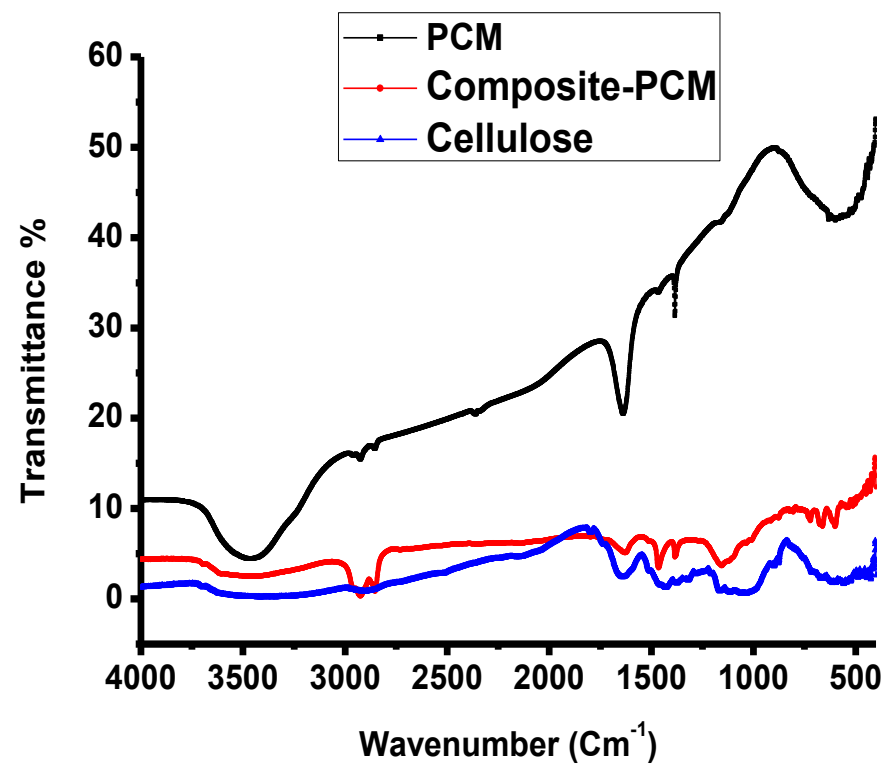

Fig 6. FT-IR spectra of PCM, cellulose fibers and composite-PCM.

\subsection{XRD for crystallographic structure analysis}

Fig 7 shows the XRD pattern of the experimented composite-PCM. As can be observed from fig 7 , the XRD pattern displays significant peaks at approximately all $3^{\circ}$, from $20^{\circ} \sim 32^{\circ}$. The peaks are reported at around $\left(21^{\circ}, 24^{\circ}, 26^{\circ}, 29^{\circ}, 32^{\circ}\right)$. The result can mean that the composite-PCM has a regular crystallization. The peaks become less distinguish than the first ones more than $32^{\circ}$. It can be related to the fact that the amount of the crystalline material decreased due to the melting of the PCM. So, the XRD peaks at $\left(36^{\circ}, 38^{\circ}, 42^{\circ}\right.$, and $\left.48^{\circ}\right)$ are caused by the plaster molecules. 


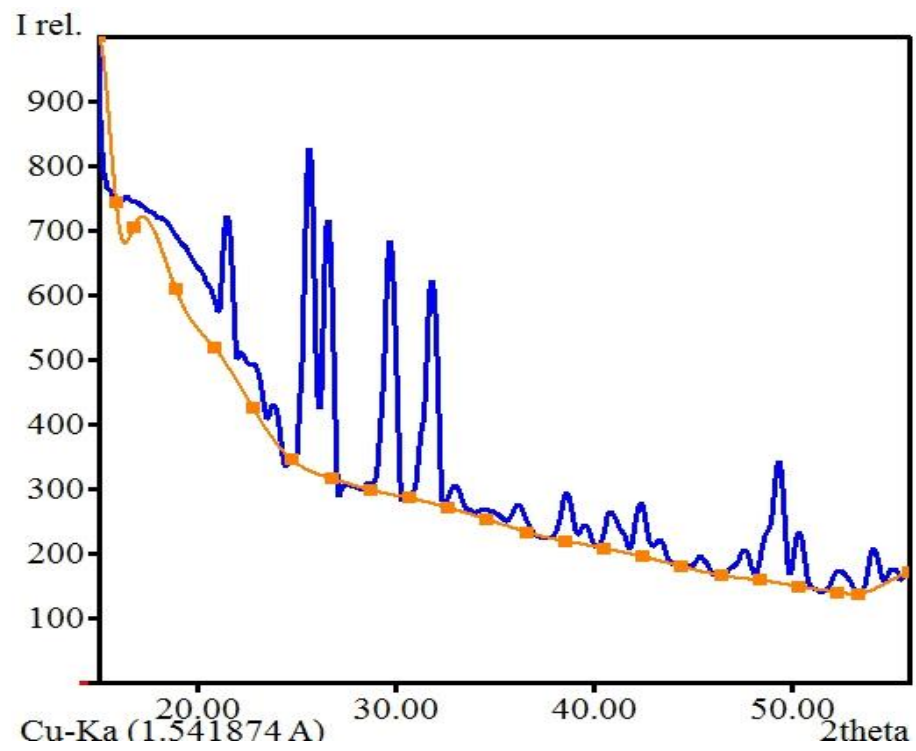

Fig 7. XRD pattern of the composite-PCM.

\subsection{TGA for thermal reliability analysis}

Fig 8 shows the TGA curve of the prepared composite-PCM. The curve displays weight loss stages of approximately $8 \mathrm{mg}$ of the novel material as a function of temperature evolution.

As can be seen from Fig 8, the weight loss is really insignificant below $120{ }^{\circ} \mathrm{C}$. The few weight loss reported at $100^{\circ} \mathrm{C}$ corresponds to the evaporation of the water contained in the pores of the sample. The first stage of weight loss occurs between $180{ }^{\circ} \mathrm{C} \sim 250{ }^{\circ} \mathrm{C}$; it corresponds to the thermal degradation of paraffin. The weight loss reported at $260{ }^{\circ} \mathrm{C}$ to $340{ }^{\circ} \mathrm{C}$ is related to the deterioration of cellulose fibers. The last stage takes place more than $400^{\circ} \mathrm{C}$ and it corresponds to the deterioration of molecules of plaster.

No weight loss of the experimented material is recorded below $100^{\circ} \mathrm{C}$. The result means that the material can be used for building applications without any risk of thermal degradation. As a conclusion, the composite-PCM is thermally stable in its working temperature range.

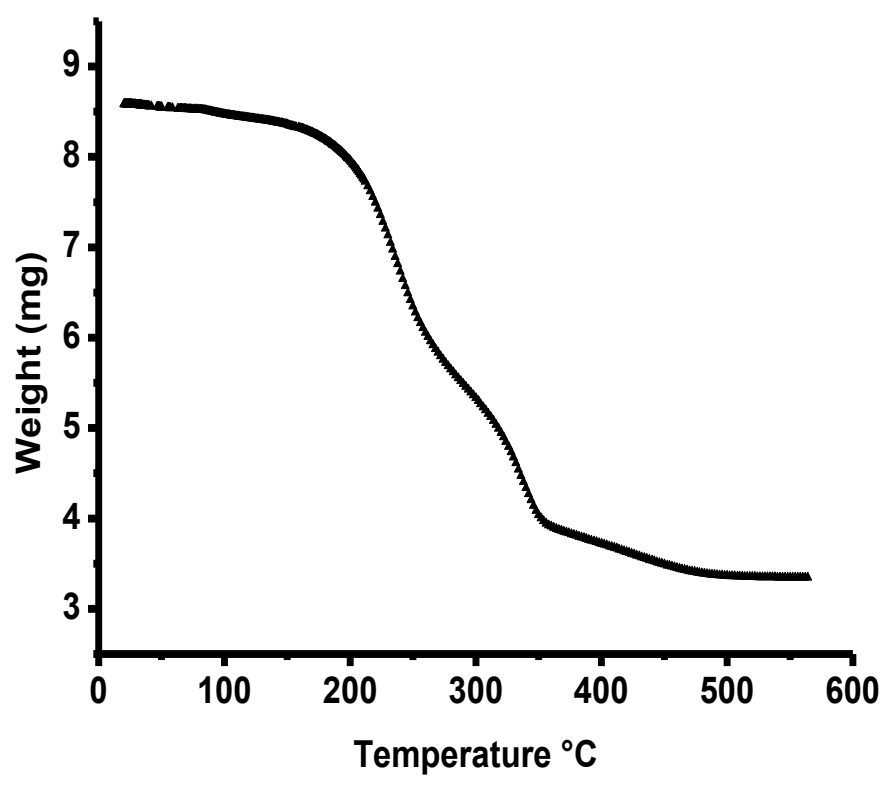

Fig 8. TGA curve of the composite-PCM. 


\subsection{DSC for thermal properties analysis}

Fig 9 shows the DSC curves of the PCM and the composite-PCM. As can be seen from Fig 9, two different peaks are distinguished on each curve of the PCM and the composite PCM. The first small peaks take place at around $10 \sim 15^{\circ} \mathrm{C}$ on both the DSC curve of the PCM and the compositePCM and they correspond to the solid-solid transformations of the PCM and the composite-PCM (Srivastava et al., 1993). The second ones are more important than the firsts; they are reported at temperatures between $20^{\circ} \mathrm{C}$ to $40^{\circ} \mathrm{C}$ and they correspond to the melting peaks of the PCM and the composite PCM. As the PCM used is not a pure substance; there is no distinct melting point of the substance but a large band of fusion is recorded. The melting of the PCM starts at $21.75^{\circ} \mathrm{C}$ and its fusion occurs at around $32.5^{\circ} \mathrm{C}$ with a latent heat of fusion of $183.99 \mathrm{~J} / \mathrm{g}$. the fusion of the composite-PCM begins at $23.05{ }^{\circ} \mathrm{C}$ and it takes place really at around $36^{\circ} \mathrm{C}$ with a latent heat of fusion of $130.57 \mathrm{~J} / \mathrm{g}$.

Table 3 recapitulates the corresponding melting temperatures and the latent heat of fusion of both the PCM and the composite-PCM. Table 4 compares the results of this study to those of other studies found in the literature.

Table 3. Thermal properties of the PCM and the composite-PCM.

\begin{tabular}{|c|c|c|}
\hline Samples & Melting points $\left({ }^{\circ} \mathrm{C}\right)$ & Latent Heat capacity $(\mathrm{J} / \mathrm{g})$ \\
\hline \hline PCM (Paraffin) & 32.5 & 183.99 \\
\hline Composite-PCM & 36 & 130.57 \\
\hline
\end{tabular}

Table 4. Comparison of thermal properties of the prepared composite-PCM with that of some other studies.

\begin{tabular}{|c|c|c|c|}
\hline Samples & Melting points $\left({ }^{\circ} \mathrm{C}\right)$ & $\begin{array}{c}\text { Latent heats of fusion } \\
\text { (J/g) }\end{array}$ & References \\
\hline \hline Paraffin/montmorillonite/graphite. & 45.3 & 112.79 & Kao et al. 2012 \\
\hline $\begin{array}{c}\text { Wallboard impregnated with } \\
\text { Methyl palmitate-stearate. }\end{array}$ & 22.94 & 51.85 & $\begin{array}{c}\text { Feldman et al., } \\
1995\end{array}$ \\
\hline $\begin{array}{c}\text { Dodecanol/ Montmonrillonite. } \\
\text { Butyle stearate/ Montmonrillonite. }\end{array}$ & 44.1 & 74.29 & Fang et al 2008 \\
\hline $\begin{array}{c}\text { Composite plaster/ cellulose } \\
\text { fibers/paraffin }\end{array}$ & 32.5 & 79.25 & Fang et al 2006 \\
\hline
\end{tabular}

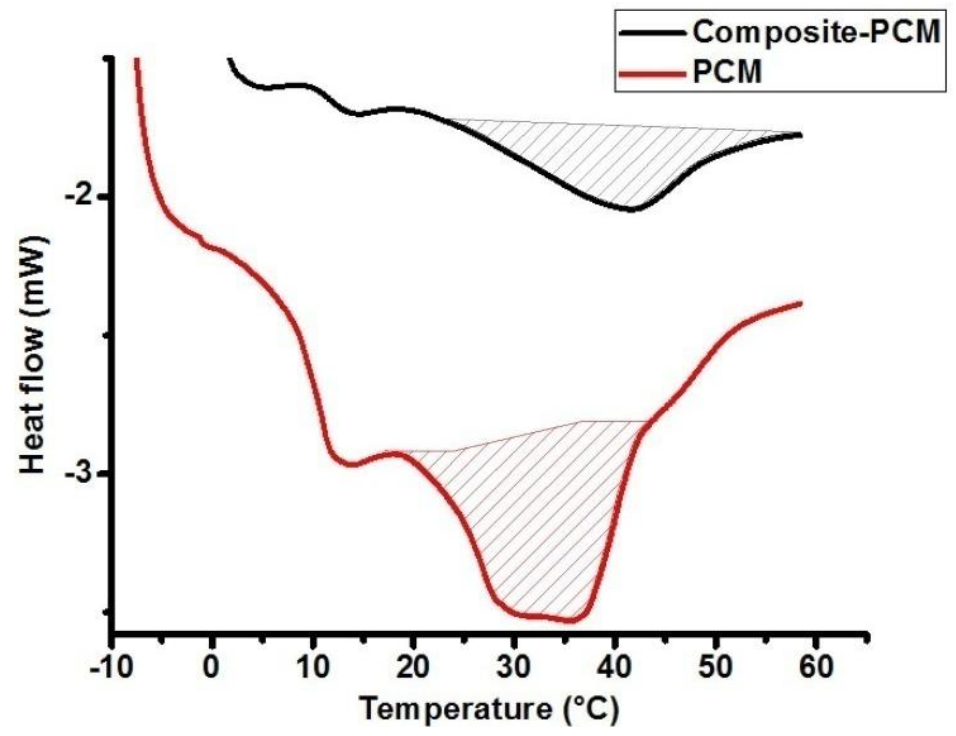

Fig 9. DSC curves of the PCM and the composite-PCM. 


\subsection{Thermal performance analysis of the composite-PCM}

Fig. 10 shows the curves of temperature evolution inside two samples of the experimented materials: Fig 10 (A) corresponds to the pellet which contains the PCM; Fig 10 (B) is the curve of the pellet which does not contain PCM.

The temperature evolution is measured using thermocouples placed in the same places of the two samples: The first thermocouples (1 and 6) are placed in the respective samples' low faces which are in direct contact with the heat source. Thermocouples ( 2 and 5) are placed in the middle layers of the samples (intermediate faces) and thermocouples ( 3 and 4 ) are placed on the samples (upper faces).

As seen from fig 10, the temperatures of the three faces of the sample B (without PCM) exceed the temperatures recorded on the sample A (with PCM) with about $8^{\circ} \mathrm{C}$. The temperature of the sample " $A$ " is clearly lower than the temperature of the sample " $B$ ". In addition, the temperature of the sample " $A$ " remains constant over a fairly large time interval; it is due to the phase change process of the PCM from the solid state to the liquid state at a temperature of $32.5^{\circ} \mathrm{C}$. Unlike the sample $A$, the stabilization of the temperature in the sample $B$ at around $50^{\circ} \mathrm{C}$ is due to the action of the hotplates' thermostat at $50^{\circ} \mathrm{C}$.

DSC analysis results confirm that the stabilization of temperature at $32.5^{\circ} \mathrm{C}$ in sample $\mathrm{A}$ is due to the phase change process. The result means that the incorporation of the PCM in traditional building materials improves significantly their thermal inertia. As a conclusion, the experimented composite-PCM has a good thermal inertia, so, it has the potential to be a good candidate for an application of improving thermal comfort in buildings and saving energy.
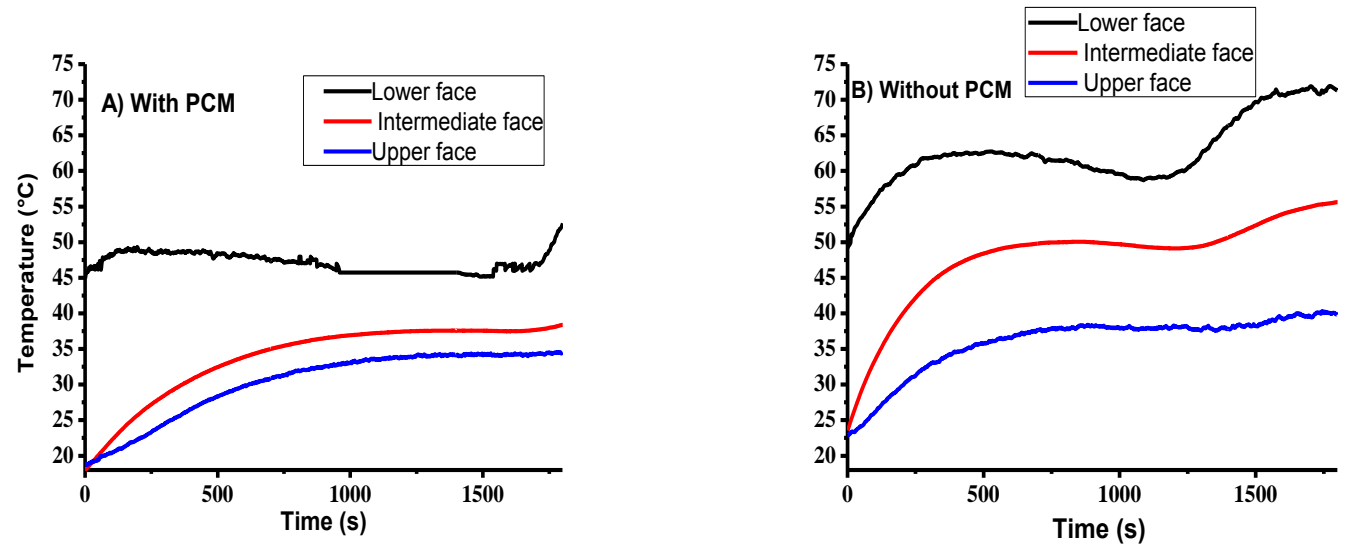

Fig 10. Comparison of the temperature evolution into two samples: A) sample with PCM, B) sample without PCM.

\section{Conclusions}

This study encompassed the elaboration and characterization processes of a novel compositePCM for building applications. The composite-PCM is prepared from a matrix impregnated with paraffin (PCM) with a melting temperature range of $32.5^{\circ} \mathrm{C}$. The matrix is composed of plaster, cellulose fibers and graphite. The PCM is incorporated in its matrix following the single face immersion process.

ESEM micrographs show that the PCM is successfully confined in its matrix, it is uniformly distributed in the microstructure and it is retained thanks to the capillary and surface tension forces.

The chemical characterization by FT-IR and XRD reveals that the novel composite-PCM is chemically stable. The result of thermal characterization by TGA confirms that the material is 
thermally stable above its working temperature range.

The temperatures recorded on the novel composite-PCM compared to those recorded on the composite material without PCM after having exposed them simultaneously to a heat source; show that the composite-PCM has a higher thermal mass. $8^{\circ} \mathrm{C}$ of temperatures' difference is recorded between the two samples; in addition the temperature of the composite-PCM remains constant over a time interval.

As a conclusion, the ability of the composite-PCM to maintain the thermal comfort without air conditioning systems is evident and the energy needed for cooling may be saved.

Researches in this field may work to find other organic PCMs as paraffin because of their excellent mixing properties with building materials. In addition, focused attention on searching the appropriate practical building applications of the composite-PCM must be made.

\section{References}

Berroug, F., Lakhal, E. K., El Omari, M., Faraji, M., \& El Qarnia, H. (2011). Thermal performance of a greenhouse with a phase change material north wall. Energy and Buildings, 43(11), 3027-3035.

Bories, C., Borredon, M. E., Vedrenne, E., \& Vilarem, G. (2014). Development of eco-friendly porous fired clay bricks using pore-forming agents: A review. Journal of environmental management, 143, 186196.

Cabeza, L. F., Castell, A., Barreneche, C. D., De Gracia, A., \& Fernández, A. I. (2011). Materials used as PCM in thermal energy storage in buildings: a review. Renewable and Sustainable Energy Reviews, 15(3), $1675-1695$.

Fang, X., \& Zhang, Z. (2006). A novel montmorillonite-based composite phase change material and its applications in thermal storage building materials. Energy and Buildings, 38(4), 377-380.

Fang, X., Zhang, Z., Chen, Z. (2008). Study on preparation of montmorillonite-based composite phase change materials and their applications in thermal storage building materials. Energy Conversion and Management, 49, 718-723.

Feldman, D., Banu, D., \& Hawes, D. W. (1995). Development and application of organic phase change mixtures in thermal storage gypsum wallboard. Solar Energy Materials and Solar Cells, 36(2), 147157.

Garg H.P., Mullick S.C., \& Bhargava A.K. (1985). Solar Thermal Energy Storage, D. Reidel Publishing Company, Dordrecht, Holland.

Hinterstoisser, B., Åkerholm, M., \& Salmén, L. (2001). Effect of fiber orientation in dynamic FTIR study on native cellulose. Carbohydrate Research, 334(1), 27-37.

Kao, H., Li, M., Lv, X., \& Tan, J. (2012). Preparation and thermal properties of expanded graphite/paraffin/organic montmorillonite composite phase change material. Journal of thermal analysis and calorimetry, 107(1), 299-303.

Klemm, D., Heublein, B., Fink, H. P., \& Bohn, A. (2005). Cellulose: fascinating biopolymer and sustainable raw material. Angewandte Chemie International Edition, 44(22), 3358-3393.

Pasupathy, A., Velraj, R., \& Seeniraj, R. V. (2008). Phase change material-based building architecture for thermal management in residential and commercial establishments. Renewable and Sustainable Energy Reviews, 12(1), 39-64.

Petersson, M., Gustafson, I., \& Stading, M. (2008). Comparison of microstructural and physical properties of two petroleum waxes. Journal of Materials Science, 43(6), 1869-1879.

Pielichowska, K., \& Pielichowski, K. (2014). Phase change materials for thermal energy storage. Progress in materials science, 65, 67-123.

Sarı, A., \& Karaipekli, A. (2007). Thermal conductivity and latent heat thermal energy storage characteristics of paraffin/expanded graphite composite as phase change material. Applied Thermal Engineering, 27(8-9), 1271-1277. 
Sharma, A., Tyagi, V. V., Chen, C. R., \& Buddhi, D. (2009). Review on thermal energy storage with phase change materials and applications. Renewable and Sustainable energy reviews, 13(2), 318-345.

Srivastava, S. P., Handoo, J., Agrawal, K. M., \& Joshi, G. C. (1993). Phase-transition studies in n-alkanes and petroleum-related waxes-A review. Journal of Physics and Chemistry of Solids, 54(6), 639-670.

Voelker, C., Kornadt, O., \& Ostry, M. (2008). Temperature reduction due to the application of phase change materials. Energy and Buildings, 40(5), 937-944.

Wahid, M. A., Hosseini, S. E., Hussen, H. M., Akeiber, H. J., Saud, S. N., \& Mohammad, A. T. (2017). An overview of phase change materials for construction architecture thermal management in hot and dry climate region. Applied Thermal Engineering, 112, 1240-1259.

Zalba, B., Marın, J. M., Cabeza, L. F., \& Mehling, H. (2003). Review on thermal energy storage with phase change: materials, heat transfer analysis and applications. Applied thermal engineering, 23(3), 251-283.

Zhou, D., Zhao, C. Y., \& Tian, Y. (2012). Review on thermal energy storage with phase change materials (PCMs) in building applications. Applied energy, 92, 593-605. 